\title{
CORROSION OF 1.4110 STAINLESS STEEL AT NITRATE ACID AT 323 K
}

\author{
Tomasz Kruszewski, Tomasz Lipinski \\ University of Warmia and Mazury in Olsztyn, Poland \\ tomasz.kruszewski@uwm.edu.pl, tomaszlipinski.tl@gmail.com
}

\begin{abstract}
Corrosion is a common process of destroying construction materials. The material during these processes loses its properties, it causes deterioration of functions, loses its usefulness, applicability. One of the important aggressive environments in the agricultural industry is nitrogen, from which nitric acid may be formed. Due to high hardness and also a good resistance to abrasion and corrosion the 1.4110 steel is commonly used in industry as knife blades, machining tools, measuring tools, pump construction, valves. Stainless steel is steel with good resistance to homogeneous or local environmental attack. The aim of the research was to determine the corrosive wear of 1.4110 steel (X55Cr), corrosion resistance with martensitic microstructure using the Huey test. The tested steel contains $0.52 \% \mathrm{C}, 13.4 \% \mathrm{Cr}$ and $0.65 \% \mathrm{Mo}$. The samples were weighed before start of the corrosion processes and after them. Samples were kept in nitric acid $65 \%$ at temperature $323 \mathrm{~K}$. The holding times of the samples in nitric acid were 48, 96, 144, 192, 240, 288, 336, 384 hours. The percentage of mass losses was determined by the weight method. Each sample was examined metallographically using an optical microscope and the surface roughness test using a profilometer. The test results were analyzed in order to determine the corrosion rate of steel in $\mathrm{mm} / \mathrm{year}$ and $\mathrm{g} / \mathrm{m} 2$ as well as percentage mass loss and determine the corrosion resistance in this environment. After corrosion of the steel, the roughness has increased. Mass loss and corrosion velocity were presented by a linear function, but greater accuracy is obtained by using the 3rd degree polynomial. Then it was confirmed that as the holding time in boiling nitric acid increases, corrosive wear increases. Generally, the tested steel 1.4110 has a good corrosion resistance in the nitricacid environment.
\end{abstract}

Keywords: steel, stainless steel, corrosion, corrosion rate, roughness.

\section{Introduction}

In technics corrosion mainly concerns metal materials and within them also iron alloys. Stainless steel is steel with good resistance to homogeneous or local environmental attack. Corrosion-resistant steels created have resistance only in specific conditions [1-7]. Their corrosion resistance depends i.a. on the chemical ingredients, microstructure, surface condition. Corrosion-resistant steels have at least $10.5 \%$ chromium and a maximum of $1.2 \%$ carbon, elements that conduce to forming of the surface layer (passive), with dense structure and consistent with the base, causing a jump of the chemical potential, it has a tendency to self-rebuilding and provides corrosion resistance. Along with the increasing content of the chromium, nickel, molybdenum the corrosion resistance is gaining. Corrosion is a phenomenon of material damage as a result of the chemical and electrochemical environment influence [8-12].

In alloys and metals changes occur as a result of interaction with the surrounding environment. The corrosion process begins at the point of contact with the environment, on the surface of the metal, it goes deep into the material. As a result of this process, the material loses its features until it loses usability. The progressive corrosion causes a significant reduction of usefulness and mechanical functions of machines, devices and components [13-17]. There are also economic losses that result from the corrosive use of pipelines, tanks, chemical installations, car mufflers and machine parts. Factors affecting the phenomenon of corrosion can be divided into: internal and external. Stainless steels, among metal materials, have a high corrosion resistance in many different corrosive environments because of a phenomenon called passivation. This phenomenon is creating a very thin passive layer on the surface of stainless steel, it is closely related to the base. It prevents contact between more or less aggressive environment with metal. In case of mechanical damage of the passive layer, the coating is self-rebuilding [18-26]]. Animal products and biological substances are important corrosive environmental factors in agricultural industry. Therefore, corrosion in agricultural industry is very a difficult and also dangerous process [27-32].

The environment, which agricultural machines and devices work in, is classified as very aggressive [29-32]. The reason for this, among others, is high nitrogen content in the atmosphere and in animal waste, which can form chemical compounds. Considering the wide use of stainless steel in grade 1.4110 in agricultural machinery and equipment, it was decided to check its rate of corrosion in the nitric acid environment. 


\section{Materials and methods}

The tests were performed on steel grade 1.4110 (X55Cr using the Huey test. [33]) The tested steel contained $0.52 \% \mathrm{C}, 13.4 \% \mathrm{Cr}$ and $0.65 \mathrm{Mo}$. Samples were cut from a $8 \mathrm{~mm}$ thick sheet of metal on an electrical discharge machine. In order to remove overheating after the cutting process and to make the samples with the same roughness, the steel was grinded on sandpaper with a grit size of 400 to $R_{a}>0.32 \mu \mathrm{m}$ and degreasing. Corrosion tests were conducted in nitric acid $65 \%$ pure-basic (INTRIC ACID $65 \%$ PURE P.A.-BASIC) at temperature $323 \mathrm{~K}$ in time intervals: 48 h, 96 h, $144 \mathrm{~h}, 192 \mathrm{~h}$, $240 \mathrm{~h}, 288 \mathrm{~h}, 336 \mathrm{~h}$ and $384 \mathrm{~h}$. After each of these time intervals, the samples were removed from the bath, washed with water, quenched and washed with alcohol to break the corrosion process. Mass losses after the corrosion process were determined using a KERN ALT 310-4 AM scale with an accuracy of $0.00001 \mathrm{~g}$. Metallographic studies were carried out on an Olympus IX70 microscope at magn. 5-100x. Roughness measurements were made using the DIVIATE DH-5 profilometer, recording $R_{a}$ (arithmetic mean deviation of the roughness profile), $R_{z}$ (roughness value among 10 points).

Relative mass loss of 1.4110 stainless steel grade was calculated with (1). The corrosion rate was calculated in mm per year with formula (2) or in grams per square meter with formula (3):

$$
\begin{aligned}
& r_{\text {rel }}=\frac{\Delta m}{m_{0}} 100 \%, \\
& r_{\text {corm }}=\frac{8760 \cdot m}{S \cdot t \cdot \rho}, \\
& r_{\text {corg }}=\frac{10000 \cdot m}{S \cdot t},
\end{aligned}
$$

where $\Delta m-$ loss of smple mass due to corrosion, $\mathrm{g}$;

$m_{0}$ - initial weight of sample, g;

$t$ - time of soaking in a corrosive solution of nitric acid V $65 \%$ at temperature $323 \mathrm{~K}$, hours;

$S$ - contact surface of the sample with nitric acid of the sample, $\mathrm{cm}^{2}$;

$m$ - average mass loss after the test in nitric acid V $65 \%$ at temperature $323 \mathrm{~K}$, g;

$\rho$ - tabular density of the tested steel, $\mathrm{g} \cdot \mathrm{cm}^{-3}$.

\section{Results and discussion}

Relative mass loss with standard error is presented in Fig. 1. The corrosion rate calculated in $\mathrm{mm}$ per year with formula (2) and its standard error are presented in Fig. 2 and in grams per square meter calculated with formula (3) in Fig. 3. An example of the steel surface roughness after 288 hours is shown in Fig. 4.

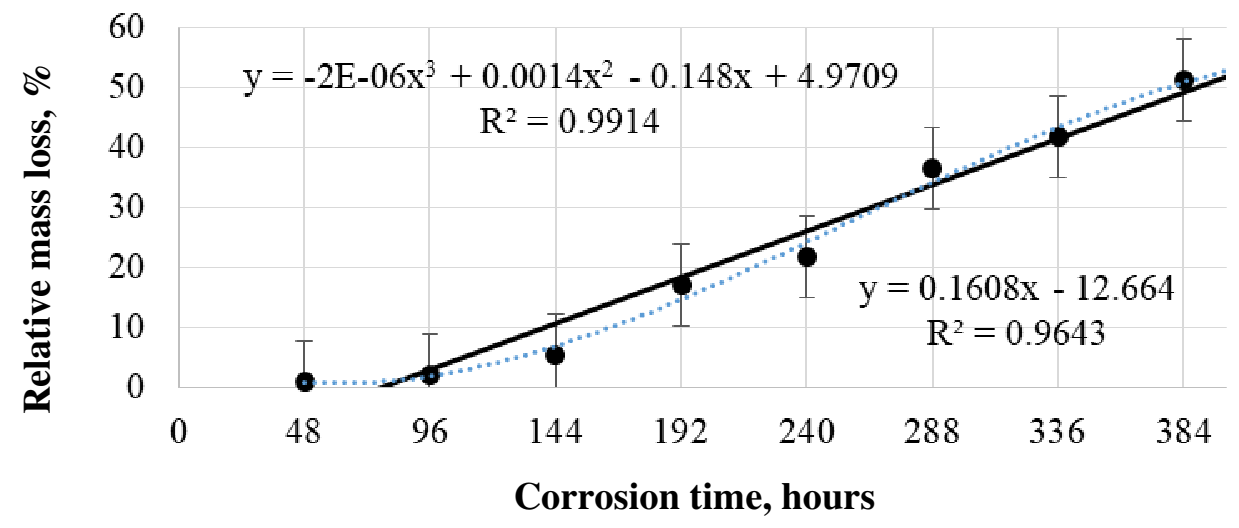

Fig. 1. Relative mass loss of 1.4110 stainless steel soaking in nitric acid $\mathrm{V} 65 \%$ at temperature $323 \mathrm{~K}$ 
After analysis of the changes of relative mass loss and corrosion rate of 1.4110 steel soaking in nitric acid V $65 \%$ at temperature $323 \mathrm{~K}$, a very slow increase of the mass loss was found for the first 96 hours (Fig. 1- Fig. 3). For the time interval of 96-144 hours a much greater increase in the corrosion rate was noticed. With further extension of the steel time in nitric acid, the analyzed mass loss and corrosion rate stabilized and to the final stage of the research $(384 \mathrm{~h})$ changes were observed oscillating around the fixed values of relative mass loss and corrosion rate. Similar to the abovedescribed processes, it was noted for the roughness parameters, mainly $R_{z}$. After analysis of the changes in the Ra parameter over time, a little slowdown was found after exceeding 240 hours of the corrosion process. It was also observed that the parameter Ra is more stable for corrosion time interval of 96 to $192 \mathrm{~h}$ and 244 to $386 \mathrm{~h}$ than the parameter $R_{z}$.

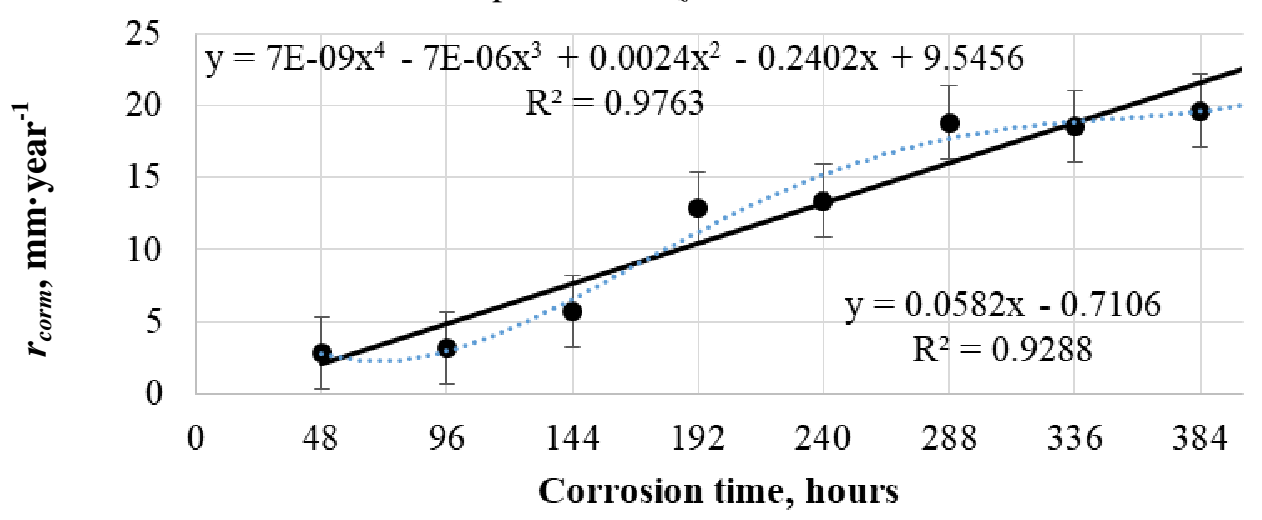

Fig. 2. Corrosion rate in $\mathbf{m m}$ per year of 1.4110 stainless steel soaking in nitric acid $V 65 \%$ at temperature $323 \mathrm{~K}$

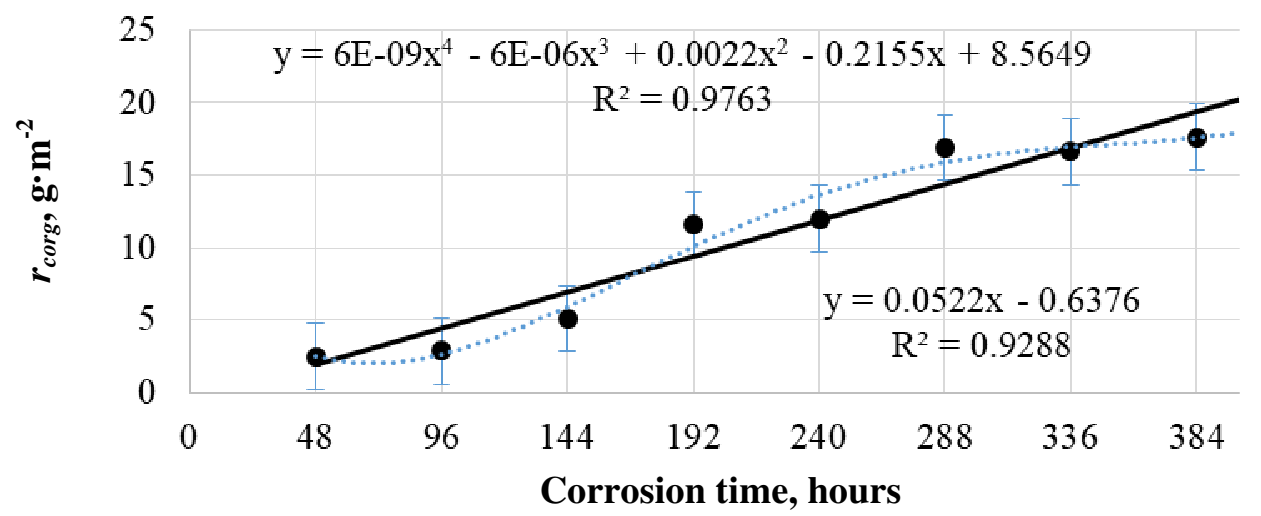

Fig. 3. Corrosion rate in grams per square meter of 1.4110 stainless steel soaking in nitric acid $\mathrm{V} 65 \%$ at temperature $323 \mathrm{~K}$

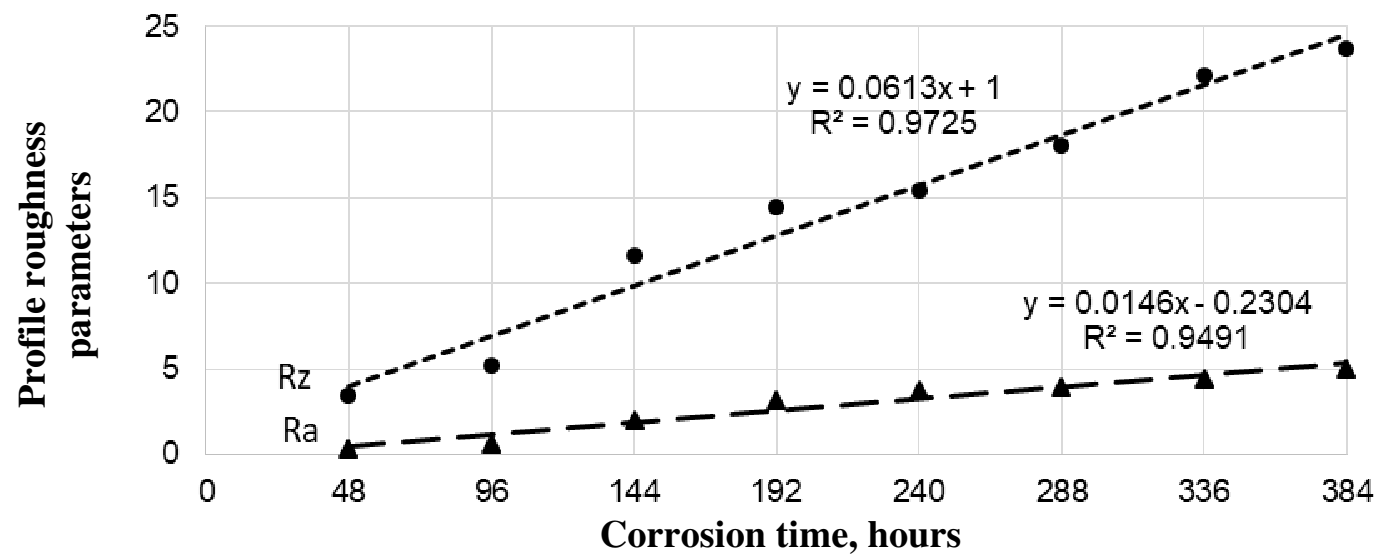

Fig. 4. Roughness parameters of $\mathbf{1 . 4 1 1 0}$ stainless steel soaking in nitric acid $\mathrm{V} 65 \%$ at temperature $323 \mathrm{~K}$ 
Relative mass loss of 1.4110 stainless steel in the first period soaking in nitric acid V $65 \%$ at temperature $323 \mathrm{~K}$ (up to 96 hours) increases slightly, then the consumption increases to 144 to 384 hours soaking (until the end of observation) achieving a constant relative mas loos. In order to better illustrate the process, apart from the linear function, the third-degree mathematical function was used (Fig. 1). Analyzing the corrosion rate change in time measured in mm per year (Fig. 2) or grams per square meter of 1.4110 stainless steel soaking in nitric acid V $65 \%$ at temperature $323 \mathrm{~K}$ in the first period (up to 96 hours) the corrosion rate increases slightly, then between 96 and 144 hours the soaking corrosion rate increases rapidly. Over a period of from 144 to 288 hours soaking the steel the corrosion rate achieved a constant (second corrosion stage) but higher than at the first stage. After exceeding 288 hours to 384 hours (until the end of observations), the corrosion rate decisively decreased, reaching a constant rate (the third stage). In order to better illustrate the process consisting of three stages, the fourth order mathematical function was used next to the linear function.

The slowdown of the roughness increase represented by the Ra parameter during the tested time interval can be explained by dissolution of protruding metal particles above the average roughness profile by nitric acid, which results in flattening of the profile and, as an effect, a slower growth of the analysed parameter, as confirmed in Fig. 5.

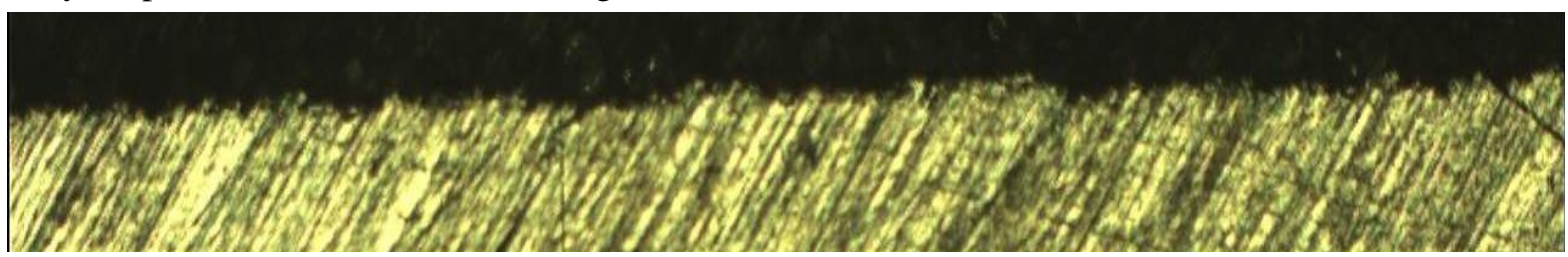

Fig. 5. Roughness of 1.4110 stainless steel soaking in nitric acid V $65 \%$ at temperature $323 \mathrm{~K}$ for $288 \mathrm{~h}$

The numerous, descriptive literature presents corrosion problems solved based on potentiostatic studies [34-37]. This approach to the problem facilitates its analysis and documentation of the process, but requires adaptation before applying the results in industrial practice. Corrosion tests presented in the paper enable direct transfer to the industry.

\section{Conclusions}

1. Tested martensitic steel 1.4110 has good corrosion resistance in the environment of nitric acid.

2. The weight loss and corrosion rate of 1.4110 steel can be presented by a linear function with sufficient statistical accuracy. However, taking into account the small lack of proportionality, greater accuracy of results of corrosion rate is obtained by using the 4th degree polynomian. The proposed 4th stage function allows to observe the three periods of corrosion and is much more accurate both for the observation of the corrosion rate as well as its numerical analysis.

3. The obtained equations can be used to model the corrosion process of 1.4110 steel in the environment of nitric acid at $323 \mathrm{~K}$.

\section{References}

[1] Pashechko M.I., Shyrokov V.V., Duryahina Z.A., Vasyliv Kh.B. Structure and corrosionmechanical properties of the surface layers of steels after laser alloying Materials Science, 39(1), 2003, pp. 108-117.

[2] Andreiko I.M., Kulyk V.V., Ostash O.P. Resistance of steels of railroad wheels to corrosionfatigue fracture Materials Science 47(5), 2012, pp. 608-612.

[3] Lipiński T. Corrosion Resistance of 1.4362 Steel in Boiling $65 \%$ Nitric Acid. Manufacturing Technology 16 (5), 2016b, pp. 1004-1009.

[4] Pitrmuc Z., Capek J., Kolarik K., Beranek L., Urban J. Tool Geometry Influence on Surface Integrity of Machined Austenite Stainless Steel. Manufacturing Technology 16(2), 2016, pp. 425-431.

[5] Kim J.S., Peeken W.H.A., Hemmes K. Effect of Alloying Elements on the Contact Resistance and the Passivation. Behaviour of Stainless Steel. Corrosion Sciences 44, 2002, pp. 635-655. 
[6] Szabracki P., Lipiński T. Effect of aging on the microstructure and the intergranular corrosion resistance of X2CrNiMoN25-7-4 duplex stainless steel. Solid State Phenomena 203-204, 2013, pp. 59-62.

[7] Walke W., Paszenda Z., Marciniak J. Corrosion resistance of Co-Cr-W-Ni alloy designer for implants used in operative cafdiology. Engineering of Biomaterials, 47-53, 2005, pp. 96-99.

[8] Zatkalíková V., Markovičová L., Chalupova M. Corrosion resistance of Cr-Ni-Mo Stainless Steel in Chloride and Fluoride Containing Environment. Manufacturing Technology 16(5), 2016, pp. 1193-1198.

[9] Madkour L.H., Hassanein A.M., Ghoneim M.M., Eid S.A. Inhibition Effect of Hydantoin Compounds on the Corrosion of Iron in Nitric and Sulfuric Acid Solutions. Monatshefte fur Chemie. 132(2), 2001, pp. 245-258.

[10] Dobrzanski L.A., Brytan Z., Grande M.A., Rosso M., Pallavicini E.J. Properties of vacuum sintered duplex stainless steels. Journal of Mechanical Working Technology 162-163, 2005, pp. 286-292.

[11]Lipiński T. Corrosion Rate of the X2CrNiMoN22-5-3 Duplex Stainless Steel Annealed at 500 degrees C. Acta Physica Polonica A 130 (4), 2015, pp. 993-995.

[12] Yang Y., Cheng Y.F. Electrolytic deposition of Ni-Co-SiC nano-coating for erosion-enhanced corrosion of carbon steel pipes in oilsand slurry. Surface \& Coatings Technology 205, 2011, pp. 3198-3204.

[13] Szabracki P., Lipiński T. 2014. Influence of sigma phase precipitation on the intergranular corrosion resistance of $\mathrm{X} 2 \mathrm{CrNiMoN25-7-4}$ super duplex stainless steel. 23rd International Conference on Metallurgy and Materials METAL 2014, pp. 476-481.

[14] Uhlig H.H., Revie R.W. Corrosion and corrosion control, 3rd Edition, John Wiley and Sons 1985.

[15] Yang Y., Cheng Y.F. Parametric effects on the erosion-corrosion rate and mechanism of carbon steel pipes in oil sands slurry. Wear 276-277, 2012, pp. 141-148.

[16] Deng B., Jiang Y.M., Gao J., Li J., Effect of annealing treatment on microstructure evolution and the associated corrosion behavior of a super-duplex stainless steel. Journal of Alloys and Compounds 493, 2010, pp. 461-464.

[17] Deng B., Wang Z., Jiang Y., Wang H., Gao J., Li J., Evaluation of localized corrosion in duplex stainless steel aged at $850{ }^{\circ} \mathrm{C}$ with critical pitting temperature measurement. Electrochimica Acta 54, 2009, pp. 2790-2794.

[18] Duryahina Z.A., Makhorkin I.M., Lazko H.V., Bychyns'kyi V.I. Evaluation of temperature fields in corrosion-resistant steels under the action of laser radiation. Materials Science 43(6), 2007, pp. 800-806.

[19] Kusmic D., Van Than D. Corrosion Resistance of Plasma Nitrided and Nitrocarburized 42CrMo4 Steel, Manufacturing Technology 17(2), 2017, pp. 211-217.

[20]Lipiński T. Corrosion Effect of $20 \% \mathrm{NaCl}$ Solution on Basic Carbon Structural S235JR Steel. 15th International Scientific Conference Engineering for Rural Development, Proceedings vol. 15, 2017, pp. 1069-1074. Jelgava, 24.-26.05.2017.

[21] Mahdi E., Rauf A., Eltai E.O. Effect of temperature and erosion on pitting corrosion of X100 steel in aqueous silica slurries containing bicarbonate and chloride content. Corrosion Science 83, 2014, pp. 48-58.

[22] Pilch O., Faltejsek P., Hrubý V., Krbat'a M. The Corrosion Resistance of Turbocharger Stator after Plasma Nitriding Process. Manufacturing Technology 17(3), 2017, pp. 360-364.

[23] Tang X., Xu L.Y., Cheng Y.F. Electrochemical corrosion behavior of X-65 steel in the simulated oil-sand slurry. II: Synergism of erosion and corrosion. Corrosion Science 50, 2008, pp. 1469-1474.

[24] Valcarce M.B., Vázquez M. Carbon steel passivity examined in solutions with a low degree of carbonation: The effect of chloride and nitrite ions. Materials Chemistry and Physics. 115(1), 2009, pp. 313-321.

[25] Leçe H.D., Emregül K.C., Atakol O. Difference in the inhibitive effect of some Schiff base compounds containing oxygen, nitrogen and sulfur donors. Corrosion Sciences 50(5), 2008, pp. 1460-1468.

[26] Cheng X.L., Ma H.Y., Chen S.H., Chen X., Chen S.H., Yang H.Q. Corrosion of Iron in Acid Solutions with Hydrogen Sulfide Corrosion Sciences 41(2), 1998, pp. 321-329. 
[27] Sha Liu, Xue Yang, The Parametric Design of the Frame of Agricultural Machinery Cab based on Analysis of Ergonomics. Manufacturing Technology 16(3), 2016, pp. 543-551.

[28] Lipiński T. Corrosion of X2CrNiMoSi18-5-3 Duplex Stainless Steel. 15th International Scientific Conference Engineering for Rural Development, Proceedings vol. 15, Jelgava, 25.-27.05.2016, pp. 946-951.

[29] Naz M.Y., Sulaiman S.A., Shukrullah S., Ghaffar A., Ibrahim K.A., AbdEl-Salam N.M. Development of erosion-corrosion mechanisms for the study of steel surface behavior in a sand slurry. Measurement 106, 2017, pp. 203-210.

[30] Song F.G., Du L.G. Erosion corrosion of low-alloy wear-resistant steels in alkaline slurry. Journal of Ironand Steel Research, International 24, 2017, pp. 1065-1072.

[31] Yu B., Li D.Y., Grondin Ame' lie. Effects of the dissolved oxygen and slurry velocity on erosioncorrosion of carbon steel in aqueous slurries with carbon dioxide and silica sand. Wear 302, 2013, pp. 1609-1614.

[32] De Belie N., Sonck B., Braam C.R., Lenehand J.J., Svennerstedte B., Richardson M. Durability of building materials and components in the agricultural environment, Part II: metal structures. J. Agric. Eng. Res. 75, 2000, pp. 333-347.

[33] PN EN ISO 3651-1, Determination of resistance to intergranular corrosion of stainless steels. Part 1: Austenitic and ferritic-austenitic (duplex) stainless steels. Corrosion test in nitric acid mediummby measurement of loss in mass (Huey test).

[34] Wharton J.A., Wood R.J.K., Mellor B.G. Wavelet analysis of electrochemical noise measurements during corrosion of austenitic and superduplex stainless steels in chloride media. In: Corrosion Science 45, 2003, pp. 97-122.

[35] Deng B., Jiang Y., Xu J., Sun T., Gao J., Zhang L., Zhang W., Li J., Application of the modified electrochemical potentiodynamic reactivation method to detect susceptibility to intergranular corrosion of a newly developed lean duplex stainless steel LDX2101. Corrosion Science 52, 2010, pp. 969-977.

[36] Perren R.A., Suter T.A., Uggowitzer P.J., Weber L., Magdowski R., Bohni H., Speidel M.O., Corrosion resistance of super duplex stainless steels in chloride ion containing environments: investigations by means of a new microelectrochemical method I. Precipitation-free states. Corrosion Science 43, 2001, pp. 707-726.

[37]Lihua Zhang, Yiming Jiang, Bo Deng, Wei Zhang, Juliang Xu, Jin Li. Effect of aging on the corrosion resistance of 2101 lean duplex stainless steel. Materials Characterization 60, 2009, pp. 1522-1528. 